\title{
Identification of DR9-restricted XAGE antigen on lung adenocarcinoma recognized by autologous CD4 T-cells
}

\author{
MICHIHIDE SHIMONO ${ }^{1,2}$, AKIKO UENAKA ${ }^{1}$, YUJI NOGUCHI ${ }^{1}$, SHUICHIRO SATO ${ }^{1}$, HIDEO OKUMURA ${ }^{3}$, \\ KAZUHIKO NAKAGAWA ${ }^{3}$, KATSUYUKI KIURA ${ }^{2}$, MITSUNE TANIMOTO $^{2}$ and EIICHI NAKAYAMA ${ }^{1}$ \\ Departments of ${ }^{1}$ Immunology, ${ }^{2}$ Internal Medicine II, and ${ }^{3}$ Surgery II, Okayama University Graduate School \\ of Medicine, Dentistry and Pharmaceutical Sciences, 2-5-1 Shikata-cho, Okayama 700-8558, Japan
}

Received November 13, 2006; Accepted December 28, 2006

\begin{abstract}
We previously demonstrated a dominant IgG response against XAGE-1b antigen in a lung cancer patient by serological analysis of antigens by recombinant expression cloning (SEREX) analysis using a cDNA library from the autologous OU-LU-6 tumor cell line. In this study, we investigated recognition of XAGE-1b on OU-LU-6 tumor by the patient CD4-expressing tumor-infiltrating lymphocytes (CD4 TIL). The response of CD4 TIL obtained from malignant pleural effusion was determined against autologous OU-LU-6 tumor cells and XAGE-1b mRNA-transfected PHA-stimulated CD4 T-cells (T-APC) from healthy individuals sharing HLA-DR with the patient by performing IFN $\gamma$ secretion and ELISPOT assays. The patient CD4 TIL recognized OU-LU-6 in an HLADR-restricted manner and XAGE- $1 b$ mRNA-transfected T-APC derived from $D R B 1 * 0901$-sharing healthy donor (HD)1 and HD2, but not $D R B 1 * 1101$-sharing HD3 or HD4. Epitope analysis using 17 18-mer peptides with 12 overlapping amino acids revealed that the CD4 TIL recognized XAGE-1b 33-49. The findings suggest that the patient CD4 T-cells recognized the XAGE-1b 33-49-related epitope on autologous OU-LU-6 tumor cells in a manner restricted by $D R^{*} 0901$.
\end{abstract}

\section{Introduction}

$X A G E-1$ was originally identified by a search for $P A G E /$ $G A G E$-related genes using an expressed sequence tag database (1) and was shown to exhibit characteristics of cancer/testis (CT)-like antigen (2). Four transcript variants, $X A G E-1 a$, $X A G E-1 b, X A G E-1 c$, and $X A G E-1 d$, have been identified and were shown to be expressed in metastatic melanoma, Ewing's sarcoma, and various epithelial tumors such as breast, lung, and prostate cancers (3-5). We recently demonstrated that $X A G E-1 b$ mRNA was a dominantly expressed transcript and

Correspondence to: Dr Eiichi Nakayama, Department of Immunology, Okayama University Graduate School of Medicine, Dentistry and Pharmaceutical Sciences, Okayama 700-8558, Japan E-mail: nakayama@md.okayama-u.ac.jp

Key words: cancer/testis antigen, XAGE, CD4 T-cell response was detected in 15 of 49 (31\%) lung cancer specimens (6). Histologically, its expression was observed in 14 of $31(45 \%)$ adenocarcinomas and 1 of $18(6 \%)$ lung cancers of other types. Immunohistochemical (IHC) analysis using a XAGE-1 monoclonal antibody (mAb) showed that most of the XAGE-1b mRNA-positive specimens expressed XAGE-1 protein. Seropositivity was observed in 5 of $56(9 \%)$ patients with adenocarcinoma, whereas none of 18 patients with lung cancers of other types produced XAGE-1b antibody. Thus, it was shown that XAGE-1b is expressed in a significant proportion of lung adenocarcinomas and is immunogenic in patients.

In the serological analysis of antigens by SEREX, we previously identified XAGE- $1 \mathrm{~b}$ as a dominant antigen using serum from a lung adenocarcinoma patient by screening a cDNA library from an autologous OU-LU-6 tumor cell line established from malignant pleural effusion (7). In this study, we investigated the response of CD4 TIL in malignant pleural effusion of a patient against an autologous OU-LU-6 tumor. The patient CD4 TIL were shown to produce IFN $\gamma$ in response to the autologous tumor and their recognition was restricted to HLA-DR. The T-cells produced IFN $\gamma$ ELISPOTs in response to $X A G E-1 b$ mRNA-transfected T-APC from HD sharing $H L A-D R B 1 * 0901$ with the patient. Furthermore, the peptide epitope recognized by the T-cells was shown to be XAGE-1b $33-49$.

\section{Materials and methods}

Patient characteristics and clinical course. Patient OU-LU-6, a 38-year-old Japanese man had back pain and visited Okayama University Hospital in September 1999. He was found to have a large hilar mass and enlarged lymph nodes in his neck. A lymph node biopsy specimen was diagnosed pathologically as poorly differentiated adenocarcinoma in October 1999. The patient developed multiple metastases in the liver and malignant pleural effusion in November 1999. Malignant pleural effusion and serum were obtained with written informed consent in February 2000. The patient died due to respiratory failure in March 2000.

Tumor cell lines. OU-LU-6, OU-LU-17, OU-LU-26, OU-LCMS and OU-LC-KI are lung adenocarcinoma cell lines established in our laboratory. Lung cancer cell lines 11-18 and 
Table I. HLA genotypes.

\begin{tabular}{lcccc}
\hline & A & B & C & DRB1 \\
\hline OU-LU-6 & $* 0201$ & $* 3501 / * 4002$ & $* 0303 / * 0304$ & $* 0901 / * 1101$ \\
OU-LU-17 & $* 2402 / * 2602$ & $* 1501 / * 4001$ & $* 0303 / * 0802$ & ND \\
OU-LU-26 & $* 0201 / * 2402$ & $* 5201 / * 6701$ & $* 0702 / * 1202$ & ND \\
OU-LC-MS & $* 2601$ & $* 4601$ & $* 0303 / * 1601$ & ND \\
OU-LC-KI & $* 0201 / * 0206$ & $* 3901$ & $* 0304 / * 1402$ & ND \\
$11-18$ & $* 0201 / * 2402$ & $* 5201 / * 5401$ & $* 0102 / * 1201$ & ND \\
PC-9 & $* 0206 / * 2402$ & $* 3901$ & $* 03 / * 0702$ & ND \\
HD1 & $* 1101 / * 2402$ & $* 4002 / * 4006$ & $* 0102 / * 0303$ & $* 0901 / * 1502$ \\
HD2 & $* 0206 / * 2402$ & $* 3501 / * 5401$ & $* 0304$ & $* 0901 / * 1401$ \\
HD3 & $* 0201 / * 2402$ & $* 1501 / * 5201$ & $* 0401 / * 1202$ & $* 1101 / * 1502$ \\
HD4 & $* 0201 / * 2402$ & $* 1501 / * 5201$ & $* 403 / * 1406$ \\
\hline
\end{tabular}

ND, not done

PC-9 have been described (8). K562 is a myeloid leukemia cell line (9). EBV-HD1 and 3 are Epstein-Barr virus (EBV)transformed B-cell lines from HD. Those cell lines were maintained in RPMI-1640 medium (Gibco, Rockville, MD) supplemented with $10 \%$ FCS (Sigma-Aldrich, St. Louis, MO).

HLA class I and class II genotypes of the tumor cell lines and HD cells were determined as described previously (10) and are listed in Table I.

Antibodies. Anti-human CD4, anti-human CD8, anti-HLA class I, anti-HLA class II, anti-DP, anti-DQ, anti-DR, FITCanti-CD4, PE-anti-CD8, FITC-anti-HLA class I, FITC-antiHLA class II, FITC-anti-DR, FITC-anti-CD40, PE-anti-CD80, FITC-anti-CD86, FITC-anti-CD95, FITC-mouse IgG1к and FITC-mouse IgG2ak monoclonal antibodies (mAbs) were purchased from BD Bioscience (San Jose, CA). Anti-human IFN $\gamma \mathrm{mAb}(1-\mathrm{D} 1 \mathrm{~K})$ was obtained from Mabtech (Stockholm, Sweden). Goat anti-rabbit IgG $(\mathrm{H}+\mathrm{L})$ conjugated with alkaline phosphatase (AP) was purchased from Southern Biotechnology (Birmingham, AL). Rabbit anti-human IFN $\gamma$ serum was prepared in our laboratory.

Peptides. Peptides were synthesized by standard solid-phase methods using N-(9-fluorenyl) methoxycarbonyl (Fmoc) chemistry in a peptide synthesizer (model AMS422: ABIMED Analysen-Technik, Langenfeld, Germany).

Plasmid construction. XAGE-1b (nt 91-395, AJ290447) and NY-ESO-1 (nt 60-610, AJ275977) cDNA were amplified by PCR using human testis cDNA and cloned into the pTnT plasmid vector designed for in vitro transcription and translation (Promega, Madison, WI). The pTnT vector contains a 5' B-globin leader sequence and a synthetic poly $(\mathrm{A})_{30}$ tail, which enhance the expression of the inserted gene.

In vitro transcription of $m R N A$. The recombinant plasmids $\mathrm{pTnT} / X A G E-1 b$ and $\mathrm{pTnT} / N Y-E S O-1$ were linearized with NdeI. In vitro transcription was done using an mMESSAGE mMACHINE T7 kit (Ambion, Austin, TX) according to the manufacturer's instructions. The resulting capped and tailed mRNA was resuspended in water and stored at $-30^{\circ} \mathrm{C}$.

Preparation of dendritic cells $(D C)$. Monocytes were isolated from peripheral blood mononuclear cells (PBMC) using anti-CD14 mAb-coated magnetic beads (MACS; Miltenyi Biotec, Auburn, CA) and cultured in RPMI-1640 medium supplemented with $10 \%$ human AB serum (Sigma-Aldrich), $10 \mathrm{ng} / \mathrm{ml}$ recombinant human (rh) GM-CSF (Kirin Brewery, Tokyo, Japan) and $10 \mathrm{ng} / \mathrm{ml}$ rhIL-4 (PeproTech, London, UK) for one week. Lipopolysaccharide (LPS) (SigmaAldrich) was added at $100 \mathrm{ng} / \mathrm{ml}$ on day 6 to induce maturation of DC. On day 7, DC were harvested.

Generation of PHA-stimulated CD4 T-cells (T-APC). CD4 T-cells purified using anti-CD4 mAb-coated magnetic beads (MACS) were cultured in RPMI-1640 medium supplemented with $10 \%$ human $\mathrm{AB}$ serum and $10 \mu \mathrm{g} / \mathrm{ml}$ phytohemagglutinin-L (PHA) (Sigma-Aldrich). On day 3, half of the medium was replaced with the medium containing rhIL-2 (20 IU/ml) (Takeda Pharmaceutical, Osaka, Japan) and rhIL-7 (20 ng/ml) (PeproTech) and this was repeated twice a week (11).

Electroporation of $m R N A$. This was done as described (12). After adding mRNA $(10 \mu \mathrm{g})$ at room temperature, T-APC were pulsed at $400 \mathrm{~V}$ for $480 \mu \mathrm{s}$ in a 0.2 -cm-gap electroporation cuvette $(200 \mu \mathrm{l})$ using an electro square porator (model ECM830: BTX, Holliston, MA).

Isolation and culture of TIL. Malignant pleural effusion was drawn in heparin. Tumors and TIL were collected by density gradient centrifugation (13). Tumor cells formed a band on the top of 75\% (density 1.055) Histopaque 1077 (Sigma-Aldrich) and a TIL-enriched fraction formed a band at the interface between 75 and 100\% (density 1.077) Histopaque 1077.

TIL were maintained in AIM-V medium (Gibco) supplemented with $10 \%$ human $\mathrm{AB}$ serum and rhIL-2 (20 IU/ml) at a concentration of $0.5-2 \times 10^{6}$ cells $/ \mathrm{ml}$ by weekly stimulation 


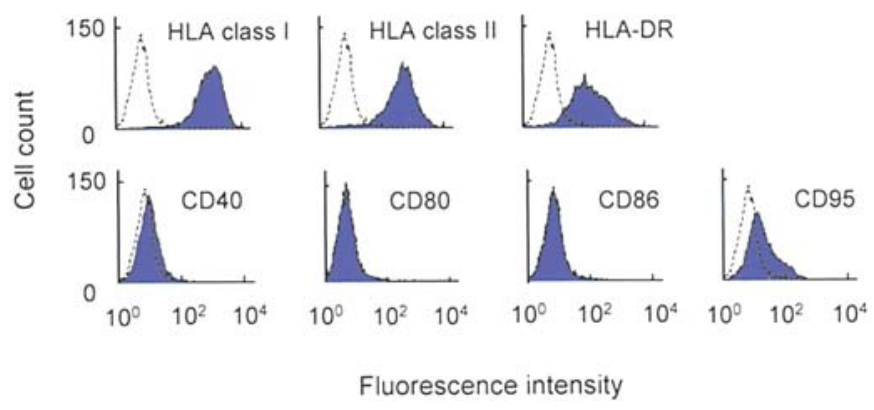

Figure 1. Flow cytometry analysis. OU-LU-6 tumor cells were stained with mAbs and analyzed using a FACScan.

with irradiated (100 Gy) OU-LU-6 tumor cells $\left(0.5-2 \times 10^{5}\right)$ in 24-well plates (Falcon, Frankline Lakes, NJ). CD4 T-cells were purified from bulk TIL using anti-CD4 mAb-coated magnetic beads (MACS) and maintained similarly to the bulk TIL.

In vitro stimulation of CD4 T-cells with peptides. For peptide pulse, cells were incubated with $10^{-5} \mathrm{M}$ peptide in X-VIVO 15 medium (Cambrex BioScience, Walkersville, MD) for $2 \mathrm{~h}$ at $37^{\circ} \mathrm{C}$. CD4 T-cells $\left(2 \times 10^{6}\right)$ were cultured with irradiated (30 Gy) peptide-pulsed DC $\left(5 \times 10^{4}\right)$ in AIM-V medium with $10 \%$ heat-inactivated pooled human serum. After a 1-week culture, responding CD4 T-cells were re-stimulated with autologous DC pulsed with the corresponding peptide. rhIL-2 $(10 \mathrm{IU} / \mathrm{ml})$ was added on the next day. For the third stimulation, irradiated (30 Gy), peptide-pulsed autologous T-APC were used as antigen presenting cells. The cultures were supplemented with $20 \mathrm{IU} / \mathrm{ml} \mathrm{rhIL-2} 1$ day after the third stimulation.

Flow cytometry analysis. For surface antigen staining, $5 \mu 1$ of mAbs were added for every set of $1 \times 10^{6}$ cells. After incubation for $30 \mathrm{~min}$, cells were washed twice with $2 \mathrm{ml}$ of PBS and fixed with $500 \mu 1$ of fixation buffer containing $0.5 \%$ paraformaldehyde. The cells were analyzed in a FACScan (Becton Dickinson, San Jose, CA) using Cell Quest software (Becton Dickinson).

Cytotoxicity assay. Cytotoxicity of the T-cells was tested in a ${ }^{51} \mathrm{Cr}$-release assay as described previously (8).

IFN $\gamma$ ELISA assay. The IFN $\gamma$ ELISA assay was performed as described previously (14). T-cells $\left(5 \times 10^{4}\right)$ and irradiated $(100 \mathrm{~Gy}) \mathrm{EBV}-\mathrm{B}$ cells $\left(5 \times 10^{4}\right)$ or tumor cells $\left(2 \times 10^{3}\right)$ were cultured in X-VIVO 15 medium in round-bottom 96-well plates for $20 \mathrm{~h}$ at $37^{\circ} \mathrm{C}$. After culturing, the supernatant was harvested and the level of IFN $\gamma$ was measured. Standard IFN $\gamma$ was purchased from PeproTech.

IFNy ELISPOT assay. ELISPOT 96-well plates (Millipore, Bedford, MA) were coated with $5 \mu \mathrm{g} / \mathrm{ml}$ anti-human IFN $\gamma$ $\mathrm{mAb}(1-\mathrm{D} 1 \mathrm{~K})$ in PBS overnight at $4^{\circ} \mathrm{C}$. Responding T-cells $\left(1 \times 10^{4}\right)$ were cultured with irradiated (100 Gy) tumor cells $\left(2 \times 10^{4}\right)$ or irradiated $(30 \mathrm{~Gy}) \mathrm{T}$-APC $\left(1 \times 10^{4}\right)$ as target cells in $\mathrm{X}$-VIVO 15 for $20 \mathrm{~h}$ at $37^{\circ} \mathrm{C}$. After washing the wells, rabbit anti-human IFN $\gamma$ serum (diluted 1:800 with PBS) was added and incubated for $2 \mathrm{~h}$ at $37^{\circ} \mathrm{C}$. After washing extensively,
AP-conjugated goat anti-rabbit IgG (diluted 1:2,000 with PBS) was added and incubated for $1 \mathrm{~h}$ at $37^{\circ} \mathrm{C}$. After washing, substrate (AP conjugate substrate kit: Bio-Rad Laboratories, Hercules, CA) was added and incubated for $20 \mathrm{~min}$ at room temperature. Spots were counted under a microscope after washing the plates.

\section{Results}

Characterization of lung cancer cell line OU-LU-6. Lung cancer cell line OU-LU-6 was established from malignant pleural effusion of a lung adenocarcinoma patient and maintained for $>5$ years. As shown in Fig. 1, OU-LU-6 cells express both HLA class I and class II, and CD40 and CD95 antigens. No expression of CD80 and CD86 was observed.

Establishment of autologous TIL line against OU-LU-6. TIL and tumor cells were obtained from pleural effusion by density gradient centrifugation. TIL were maintained in AIM-V medium supplemented with $10 \%$ human AB serum and IL-2 (20 IU/ml) by weekly stimulation with irradiated autologous OU-LU-6 as a bulk TIL line (Fig. 2A). CD4 T-cells were purified using anti-CD4 mAb-coated magnetic beads and maintained similarly to the bulk TIL. As shown in Fig. 2B, CD4-expressing TIL (CD4 TIL) produced IFN $\gamma$ upon stimulation with OU-LU-6, but not with 6 other lung cancer cell lines including OU-LU-17, OU-LU-26, OU-LC-MS, OULC-KI, 11-18 and PC-9, nor EBV-transformed HD1 or HD3 B-cell lines. No expression of HLA class II antigens was observed on the 6 tumor cell lines by FACS analysis (data not shown). As shown in Fig. 2C, the production of IFN $\gamma$ by CD4 T-cells was blocked by the addition of anti-CD4 mAb, antiHLA class II mAb and anti-HLA-DR mAb, but not anti-CD8 $\mathrm{mAb}$, anti-HLA class I mAb, anti-HLA-DP mAb or antiHLA-DQ $m A b$ to the assay culture. These findings suggested HLA-DR restricted recognition of OU-LU-6 by the patient CD4 T-cells.

We previously demonstrated a dominant $\mathrm{IgG}$ response against XAGE-1b antigen in the patient from whose pleural effusion OU-LU-6 was established by SEREX analysis using autologous sera and confirmed $X A G E-1 b$ expression on OULU-6 by RT-PCR (6). CD4 T helper cells stimulated XAGE-1b antibody production. Therefore, we investigated whether the patient bulk CD4 T-cells recognized XAGE-1b in a DRrestricted manner. For this, we used $X A G E-1 b$ mRNAtransfected T-APC obtained from normal individuals with various DR types as target cells. T-APC have previously been shown to express HLA class I, class II and CD86 (12). As shown in Fig. 2D, the patient bulk CD4 TIL line maintained by stimulation with OU-LU-6 in fact recognized XAGE-1b in a manner restricted to $D R B 1 * 0901$.

Epitope analysis. The epitope peptides recognized by the bulk CD4 T-cells were analyzed using 17 18-mer peptides with 12 overlapping amino acids using HD1 (DRB1*0901) EBV-B cells as APC. As shown in Fig. 3A, peptide 9 was recognized by bulk CD4 T-cells. Peptide 8 was weakly recognized. The minimal epitope sequence was then determined with the peptide 9 using $\mathrm{C}$ - and $\mathrm{N}$-termini truncated peptides. The response of the bulk CD4 T-cells was tested against peptide- 
A.

a.

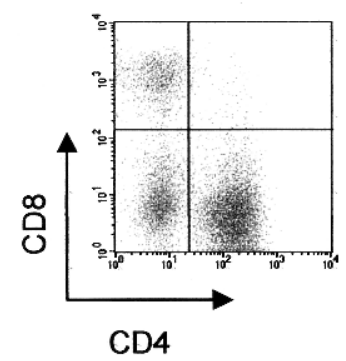

b.

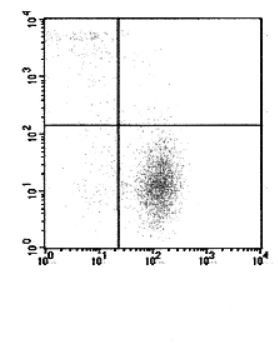

B.

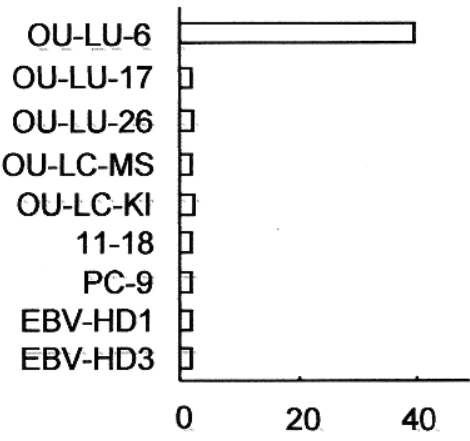

$\operatorname{IFN} r(\mathrm{ng} / \mathrm{ml})$

D.

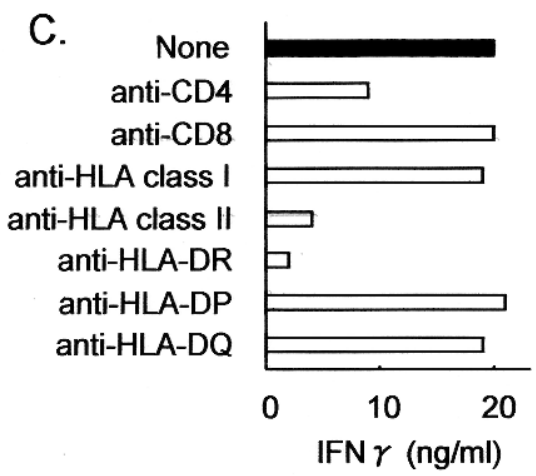

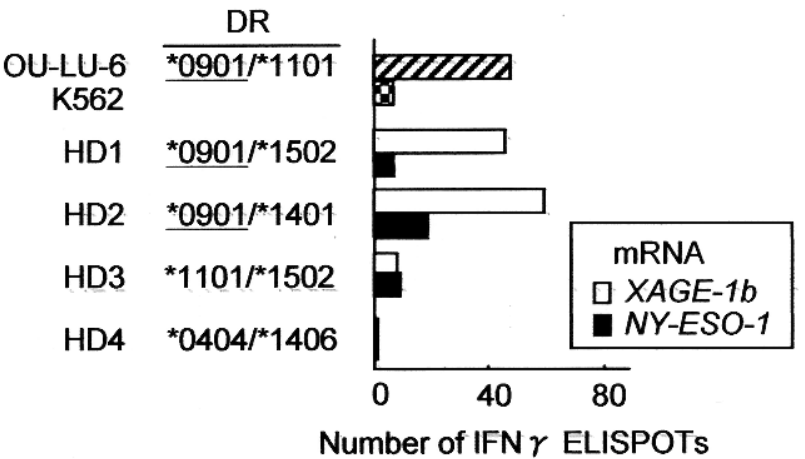

Figure 2. (A) Flow cytometry analysis of TIL (a) obtained from malignant pleural effusion of the patient and CD4 TIL (b) purified using anti-CD4 mAbcoated magnetic beads (MACS). (B) Production of IFN $\gamma$ by CD4 TIL in response to OU-LU-6 tumor cells. CD4 TIL (2x10 $\left.{ }^{6}\right)$ were maintained by weekly stimulation with irradiated (100 Gy) OU-LU-6 tumor cells $\left(2 \times 10^{5}\right)$ in 24 -well plates. The cells $\left(5 \times 10^{4}\right)$ were harvested and stimulated with irradiated (100 Gy) tumor target cells $\left(2 \times 10^{3}\right)$ or EBV-B cells $\left(5 \times 10^{4}\right)$ in round-bottom 96-well plates for $20 \mathrm{~h}$ and the supernatant was assayed for IFN $\gamma$ by ELISA. Values are the means of duplicate culture. (C) Antibody blocking. CD4 TIL $\left(5 \times 10^{4}\right)$ were stimulated with irradiated (100 Gy) OU-LU-6 tumor cells (2x10 $\left.{ }^{3}\right)$ in 96-well plates for $20 \mathrm{~h}$ in the presence of $10 \mathrm{ng} / \mathrm{ml} \mathrm{mAbs}$ and the supernatant was assayed for IFN $\gamma$ by ELISA as above. (D) CD4 TIL (1x10 $)$ were stimulated with irradiated

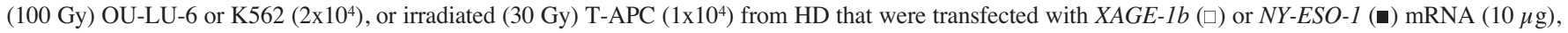
and assayed for IFN $\gamma$ ELISPOT

pulsed HD1 T-APC $(D R B 1 * 0901)$ by the IFN $\gamma$ ELISPOT assay. As shown in Fig. 3B, truncation of 4 amino acids from the C-terminus caused loss of the stimulatory activity, while the truncation of 1 amino acid from the N-terminus caused loss of the stimulation. Thus, the minimal epitope sequence recognized by the bulk CD4 T-cells is likely to be XAGE-1b 33-46.

Recognition by HD1 CD4 T-cells stimulated with peptide 9 of XAGE-1b mRNA-transfected autologous DC. HD1 CD4 T-cells were purified using anti-CD4 mAb-coated magnetic beads and stimulated with XAGE-1b 33-49 (peptide 9)-pulsed autologous DC twice and then T-APC once weekly and tested for recognition of the peptide by the IFN $\gamma$ ELISPOT assay. As shown in Fig. 4, recognition by the CD4 T-cells of XAGE-1b 33-49 (peptide 9) was observed. Recognition of XAGE-1b mRNA-transfected autologous T-APC was then examined. $X A G E-1 b$ mRNA-transfected, but not untransfected autologous T-APC were recognized, suggesting that the XAGE-1b 33-49 (peptide 9)-related epitope was processed naturally.

\section{Discussion}

We previously demonstrated that a dominant $\mathrm{IgG}$ response was observed against XAGE-1b in a lung cancer patient by
SEREX analysis using a cDNA library from the autologous OU-LU-6 tumor cell line. In this study, we showed that the patient CD4 TIL obtained from malignant pleural effusion produced IFN $\gamma$ in response to autologous OU-LU-6 tumor. The response was blocked in an HLA-DR-restricted manner. The patient CD4 TIL produced IFN $\gamma$ in response to $X A G E-1 b$ mRNA-transfected T-APC derived from $D R B 1 * 0901$-sharing, but not $D R B 1 * 1101$-sharing normal individuals. These findings suggested that the patient CD4 T-cells recognized XAGE-1b antigen on OU-LU-6 tumor cells in a manner restricted by $D R^{*} 0901$. Epitope analyses using 17 18-mer peptides with 12 overlapping amino acids revealed that the CD4 TIL recognized XAGE-1b 33-49. The minimal peptide sequence recognized by the CD4 T-cells was determined to be XAGE-1b 33-46 by using $\mathrm{N}$ - and $\mathrm{C}$-terminal truncated peptides. Furthermore, stimulation of $D R B 1 * 0901$-positive HD1 CD4 T-cells with XAGE-1b 33-49 peptide resulted in recognition of the peptidepulsed and XAGE-1b mRNA-transfected autologous T-APC, suggesting that XAGE-1b 33-49-related epitope was processed naturally.

The $\mathrm{IgG}$ response results from the activation of CD4 T helper cells. The findings that CD4 TIL in the patient recognized XAGE-1b antigen on the OU-LU-6 cell surface in a manner restricted by DR suggested that the dominant $\mathrm{IgG}$ 
A.

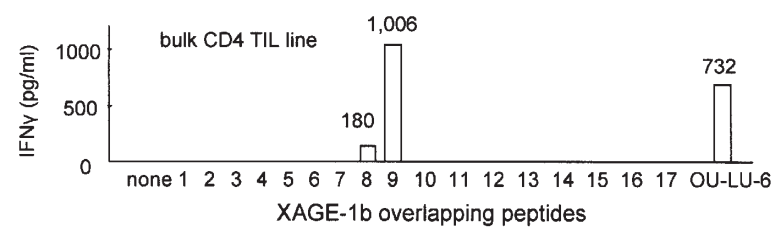

B.

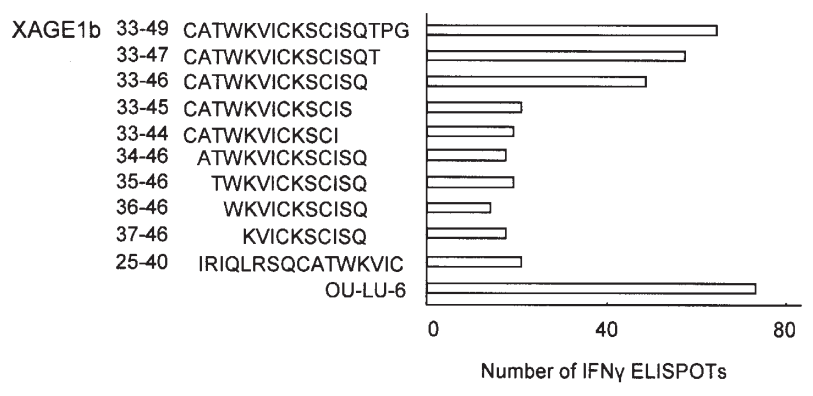

Figure 3. (A) Recognition of XAGE-1b by bulk CD4 TIL was analyzed using 17 18-mer XAGE-1b overlapping peptides. HD1 (DRB*0901) EBV-B cells were used as APC. CD4 TIL $\left(5 \times 10^{4}\right)$ were stimulated with irradiated (100 Gy), peptide $\left(10^{-5} \mathrm{M}\right)$-pulsed HD1 (DRB $\left.1 * 0901\right)$ EBV-B cells $\left(5 \times 10^{4}\right.$ cells) in 96 -well plates for $20 \mathrm{~h}$ and the supernatant was assayed for IFN $\gamma$ by ELISA. Values are the means of duplicate cultures. (B) Minimal epitope analysis. CD4 TIL $\left(1 \times 10^{4}\right)$ were cultured with irradiated $(30 \mathrm{~Gy})$, peptide $\left(10^{-5} \mathrm{M}\right)$ pulsed HD1 T-APC $\left(1 \times 10^{4}\right)$ for $20 \mathrm{~h}$ in 96-well ELISPOT plates and the number of spots was counted microscopically. Values are the means of duplicate cultures.

response to XAGE-1b antigen shown in this patient by SEREX analysis (7) resulted from the activation of CD4 T-cells against the same antigen. HLA class II antigen expression was observed on OU-LU-6. This may greatly facilitate the activation of CD4 T-cells and may have resulted in the vigorous antibody response observed in this patient. In this regard, it should be further investigated whether serum antibody response against the tumor antigen in the patient was related to the expression of HLA class II antigen on the tumor with the relevant antigen.

$X A G E-1 b$ mRNA expression is observed at a significant frequency in lung $(15 / 49,31 \%)(6)$, liver $(13 / 39,33.3 \%)$, and prostate $(14 / 54,25.9 \%)$ cancers, and at a low frequency in breast cancer $(1 / 20,5 \%)$. On the other hand, XAGE-1b protein expression has been observed only in lung cancer, with most lung cancers expressing $X A G E-1 b$ mRNA, with a few exceptions, as shown by IHC using USO 9-13 mAb. Moreover, the patients who showed an antibody response against XAGE-1b antigen were those with lung cancer (6). These findings suggest that XAGE-1b expression is unique to lung cancers. Among lung cancers, its expression was mostly observed in adenocarcinomas.

Expression of CT antigens was observed at a high frequency in lung cancers (15). Among CT antigens, MAGEA3 is one of the most commonly expressed, but a spontaneous humoral immune response to the antigen is rarely observed in patients (16). NY-ESO-1 is less frequently expressed, but has been shown to induce frequent and spontaneous antibody, CD4, and CD8 T-cell responses in a Caucasian population of
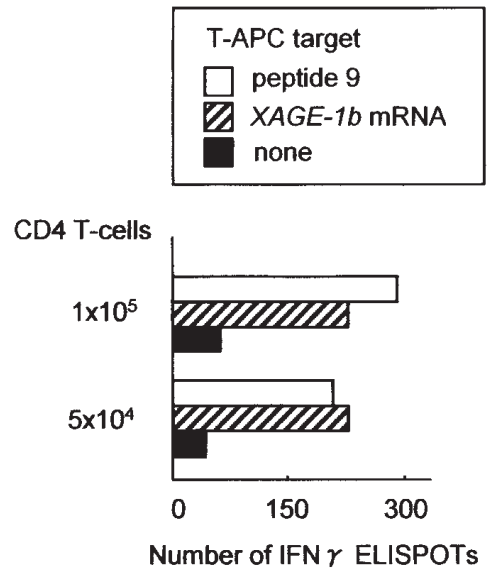

Figure 4. HD1 CD4 T-cells $\left(1 \times 10^{6}\right)$ were cultured with irradiated (30 Gy), XAGE-1b 33-49 (peptide 9)-pulsed autologous DC $\left(5 \times 10^{4}\right)$ twice and then PHA-simulated T-APC $\left(1 \times 10^{5}\right)$ once weekly. The cells were harvested and stimulated with irradiated (30 Gy), peptide $\left(10^{-5} \mathrm{M}\right)$-pulsed or XAGE-1b mRNA $(10 \mu \mathrm{g})$-transfected HD1 T-APC $\left(1 \times 10^{4}\right)$ in 96-well ELISPOT plates for $20 \mathrm{~h}$, and the number of spots was counted microscopically. Values are the means of duplicate cultures.

patients $(17,18)$. However, in the Japanese population, the frequency of NY-ESO-1 expression is low $(\sim 5 \%)$ in lung cancer, comparing to a frequency of $\sim 30 \%$ in Caucasians. We observed antibody production against XAGE-1b in 5 of 56 patients with adenocarcinoma but not in 18 patients with other histological types or 40 healthy donors. These findings indicated that XAGE-1b expressed in lung adenocarcinoma was strongly immunogenic in patients. XAGE-1b may therefore be a promising candidate target for immunotherapy (19).

Finally, we characterized the $D R * 0901$-binding XAGE$1 \mathrm{~b}$ peptide recognized by CD4 T-cells. The finding that the $D R^{*} 0901$-positive healthy donor CD4 T-cells stimulated with the peptide also recognized $X A G E-1 b$ mRNA-transfected T-APC suggested that the peptide-related epitope was the naturally processed antigen. Many CD4 and CD8 T-cell epitopes on various tumor antigens have been identified (20-23). The peptide epitope identified in this study is the first T-cell epitope defined on XAGE-1b.

\section{Acknowledgements}

We thank M. Isobe and T. Akimoto for their excellent technical assistance and J. Mizuuchi for preparation of the manuscript. This study was supported by Scientific Research on Priority Areas from the Ministry of Education, Culture, Sports, Science and Technology of Japan and the Cancer Research Institute, New York.

\section{References}

1. Brinkmann U, Vasmatzis G, Lee B and Pastan I: Novel genes in the PAGE and GAGE family of tumor antigens found by homology walking in the dbEST database. Cancer Res 59: $1445-1448,1999$

2. Liu XF, Helman LJ, Yeung C, Bera TK, Lee B and Pastan I: XAGE-1, a new gene that is frequently expressed in Ewing's sarcoma. Cancer Res 60: 4752-4755, 2000. 
3. Zendman AJ, van Kraats AA, den Hollander AI, Weidle UH, Ruiter DJ and van Muijen GN: Characterization of XAGE-1b, a short major transcript of cancer/testis-associated gene XAGE-1, induced in melanoma metastasis. Int J Cancer 97: 195-204, 2002.

4. Zendman AJ, Van Kraats AA, Weidle UH, Ruiter DJ and Van Muijen GN: The XAGE family of cancer/testis-associated genes: alignment and expression profile in normal tissues, melanoma lesions and Ewing's sarcoma. Int J Cancer 99: 361-369, 2002.

5. Egland KA, Kumar V, Duray P and Pastan I: Characterization of overlapping XAGE-1 transcripts encoding a cancer testis antigen expressed in lung, breast, and other types of cancers. Mol Cancer Ther 1: 441-450, 2002.

6. Nakagawa K, Noguchi Y, Uenaka A, Sato S, Okumura H, Tanaka M, Shimono M, Ali ElDib AM, Ono T, Ohara N, Yoshino T, Yamashita K, Tsunoda T, Abe M, Shimizu N and Nakayama E: XAGE-1 expression in non-small cell lung cancer and antibody response in patients. Clin Cancer Res 11: 5496-5503, 2005.

7. Ali ElDib AM, Ono T, Shimono M, Kaneko M, Nakagawa K, Tanaka R, Noguchi Y and Nakayama E: Immunoscreening of a cDNA library from a lung cancer cell line using autologous patient serum: identification of XAGE-1b as a dominant antigen and its immunogenicity in lung adenocarcinoma. Int $\mathbf{J}$ Cancer 108: 558-563, 2004.

8. Takaki T, Hiraki A, Uenaka A, Gomi S, Itoh K, Udono H, Shibuya A, Tsuji T, Sekiguchi S and Nakayama E: Variable expression on lung cancer cell lines of HLA-A2-bind MAGE-3 peptide recognized by cytotoxic T lymphocytes. Int J Oncol 12: 1103-1109, 1998

9. Lozzio BB and Lozzio CB: Human chronic myelogenous leukemia cell-line with positive Philadelphia chromosome. Blood 45: 321-334, 1975.

10. Tokunaga K, Ishikawa Y, Ogawa A, Wang H, Mitsunaga S, Moriyama S, Lin L, Bannai M, Watanabe Y, Kashiwase K, Tanaka H, Akaza T, Tadokoro K and Juji T: Sequence-based association analysis of HLA class I and II alleles in Japanese supports conservation of common haplotypes. Immunogenetics 46: 199-205, 1997.

11. Atanackovic D, Matsuo M, Ritter E, Mazzara G, Ritter G, Jäger E, Knuth A, Old LJ and Gnjatic S: Monitoring CD4+ $\mathrm{T}$ cell responses against viral and tumor antigens using $\mathrm{T}$ cells as novel target APC. J Immunol Methods 278: 57-66, 2003.

12. Britten CM, Meyer RG, Frankenberg N, Huber C and Wölfel T: The use of clonal mRNA as an antigenic format for the detection of antigen-specific T lymphocytes in IFN gamma ELISPOT assays. J Immunol Methods 287: 125-136, 2004.
13. Whiteside TL, Miescher S, MacDonald HR and Von Fliedner V: Separation of tumor-infiltrating lymphocytes from tumor cells in human solid tumors. A comparison between velocity sedimentation and discontinous density gradients. J Immunol Methods 90: 221-233, 1986.

14. Kurashige T, Noguchi Y, Saika T, Ono T, Nagata Y, Jungbluth A, Ritter G, Chen Y-T, Stockert E, Tsushima T, Kumon H, Old LJ and Nakayama E: NY-ESO-1 expression and immunogenicity associated with transitional cell carcinoma: correlation with tumor grade. Cancer Res 61: 4671-4674, 2001.

15. Scanlan MJ, Altorki NK, Gure AO, Williamson B, Jungbluth A, Chen YT and Old LJ: Expression of cancer-testis antigens in lung cancer: definition of bromodomain testis-specific gene (BRDT) as a new CT gene, CT9. Cancer Lett 150: 155-164, 2000

16. Stockert E, Jäger E, Chen YT, Chen YT, Scanlan MJ, Gout I, Karbach J, Arand M, Knuth A and Old LJ: A survey of the humoral immune response of cancer patients to a panel of human tumor antigens. J Exp Med 187: 1349-1354, 1998.

17. Gnjatic S, Atanackovic D, Jäger E, Matsuo M, Selvakumar A, Altorki NK, Maki RG, Dupont B, Ritter G, Chen YT, Knuth A and Old LJ: Survey of naturally occurring CD4 ${ }^{+} \mathrm{T}$ cell responses against NY-ESO-1 in cancer patients: correlation with antibody responses. Proc Natl Acad Sci USA 100: 8862-8867, 2003.

18. Gnjatic S, Jäger E, Chen W, Altorki NK, Matsuo M, Lee SY, Chen Q, Nagata Y, Atanackovic D, Chen YT, Ritter G, Cebon J, Knuth A and Old LJ: CD8(+) T cell responses against a dominant cryptic HLA-A2 epitope after NY-ESO-1 peptide immunization of cancer patients. Proc Natl Acad Sci USA 99: 11813-11818, 2002.

19. Gnjatic S: Immunogenic targets in non-small cell lung cancer: more is more. Clin Cancer Res 11: 5331-5332, 2005.

20. Toes RE, Ossendorp F, Offringa R and Melief CJ: CD4 T cells and their role in antitumor immune responses. J Exp Med 189: 753-756, 1999.

21. Wang RF: The role of MHC class II-restricted tumor antigens and $\mathrm{CD} 4^{+} \mathrm{T}$ cells in antitumor immunity. Trends Immunol 22: 269-276, 2001

22. Van Der Bruggen $\mathrm{P}$, Zhang Y, Chaux P, Stroobant V, Panichelli C, Schultz ES, Chapiro J, Van Den Eynde BJ, Brasseur F and Boon T: Tumor-specific shared antigenic peptides recognized by human T cells. Immunol Rev 188: 51-64, 2002

23. Paschen A, Eichmuller S and Schadendorf D: Identification of tumor antigens and T-cell epitopes, and its clinical application. Cancer Immunol Immunother 53: 196-203, 2004. 